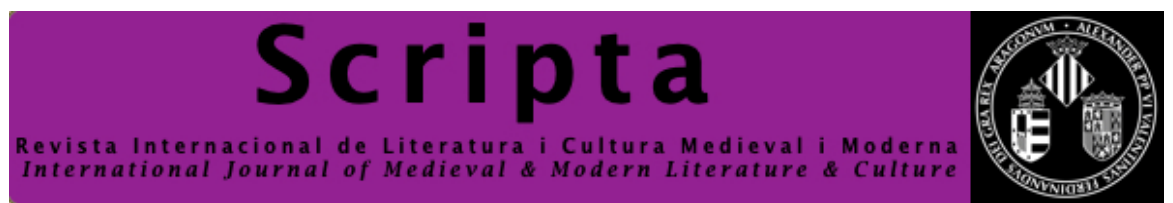

\title{
Curial e Güelfa, un nou món per a un nou cavaller: espais literaris en un entorn humanístic
}

\section{Curial e Güelfa, a new world for a new knight:ILiterary territories in a humanistic environment}

\author{
Jeroni Miguel Briongos \\ jeronimiguel@hotmail.com \\ Instituto Universitario Menéndez Pidal \\ Universidad Complutense de Madrid
}

Per a Júlla Butiny À

Resum: El Curial e Güelfa és una novel la que sorprèn per la seva modernitat. Tot i que conserva certes reminiscències medievals, com a resultat del gènere cavalleresc que la caracteritza, hem de situar-la dins de l'ambient humanista de la Itàlia del Quatttocento: tant les fonts literàries, com molts dels temes que hi apareixen, parlen d'un context social e intel lectual que es viu en aquests moment a Itàlia. El protagonista, Curial, amb el seu propòsit d'harmonitzar armes i lletres, n'és el millor exemple. El jove cavaller ha de concloure un procés de maduració personal - de crisi existencial, també- per poder assolir l'objectiu que persegueix: casar-se amb la Güelfa. Per aquesta raó, a banda de les seves gestes cavalleresques, es dedicarà a l'estudi i comprendrà que només mitjançant l'esforç que duu a la virtus podrà obtenir la necessària nobilitas que, gràcies a un procés de reconeixement del seu bomo interior, farà d'ell una persona íntegra.

Paraules clau: Humanisme, Curial, prosa acurada, armes i lletres, bivium, virtut, noblesa.

Abstract: Curial e Güelfa shocks by its own modernity. In spite of some medieval reminiscences as a result of the atmosphere of chivalry it depicts, it belongs within the humanistic influence of the Italian Quattrocento. The author's mindful prose and his selection of literary sources or the variety of themes, correspond to the social and intellectual context of the day in Italy. Curial, as the main character in the novel, is a true example in his endeavour to blend arms and letters. The young knight must undergo a process towards adulthood which will also entail a personal crisis in the quest to achieve his goal: wedding Güelfa. With this aim in mind, and along with his chivalry frays, he will bow down on study, in the understanding that virtus itself will only be achieved through exertion in order to achieve the necessary nobilitas, which will on its own turn him into an integral being after acknowledging his own bomo interior.

Keywords: Humanism, Curial, mindful prose, arms and letters, bivium, virtue, nobility.

\footnotetext{
* Treball realitzat en el marc del projecte de l'Institut Universitari Menéndez Pidal (UCM). FFI2015-63703-P (MINECO/FEDER)
} 
Jeroni Miguel Briongos. Curial e Güelfa, un nou món per a un nou cavaller: espais literaris en un entorn humanístic

\section{Una prosa senzilla i acurada}

Un dels detalls que la crítica ha destacat del Curial e Güelfa és el seu caràcter de novel la moderna que, alhora, la separa del Tirant lo Blanc i, podríem dir, que la supera. Aquesta característica, a banda dels valors intrínsecs que té l'obra pel que fa al contingut, rau en la prosa $i$ en el que podríem anomenar «estil» de l'autor; una prosa que ens parla, a més, de la formació literària de l'Anònim. D'aquesta manera, la primera impressió que rebem és la de trobar-nos davant d'una expressió clara i precisa: un llibre, en paraules d'Aramon i Serra (1930 I, 15), «ben escrit». Redactat, afegeixo, amb cura, pensant també en els possibles lectors que havia de tenir. Una llengua que expressa amb traços finíssims passions i sentiments, moments d'alegria, però també instants de naufragi emocional (pensem en les diverses situacions per les quals travessen la Güelfa, Curial, Làquesis, Càmar...), per no parlar de les pinzellades precises amb què se'ns descriuen els combats entre cavallers, especialment quan algú d'aquests enfrontaments són rellevants (és el cas de la confrontació de Curial amb Boca de Far i els respectius companys en la lluita, o la plasticitat i riquesa visual que ens permeten seguir amb detall els encontres armats del torneig de Melú). No oblidem els diàlegs, que tenen un paper no menys important en l'elaboració d'aquest entrellat formal: potser no posseeixen la vivacitat dels del Tirant, però estan plens de força expressiva, i fins i tot dramàtica, quan la situació ho requereix. La llengua és àgil i directa, si l'acció ha d'avançar; més reposada, i, en ocasions, més elevada, si ens trobem davant de parlaments o de certes descripcions. Mesurada, també, com en la narració del neguit sexual que desassossega Làquesis, follament enamorada de Curial, o quan assistim al apassionat, i a la vegada sensible i delicat, petó entre Càmar i Curial: ¿`com no evocar aquí l'instant en què la jove, un cop el seu acompanyant ha sortit de la cambra, i com volent apurar el darrer glop de felicitat que la vida li ofereix, «romàs en lo llit, lavant ab la lengua los seus labis per prendre lo çucre d'aquella poca de saliva que dels labis de Johan en los seus era romasa»? (III. 59, 335). ${ }^{1}$ Tot això amb un lèxic que, podríem dir, era comú, i oferia claus interpretatives, a cavallers, curials, lletraferits i dames de l’àmbit social en què es movia l'Anònim: ${ }^{2}$ «¿Qui ens garanteix -es demana Abel Soler (2016: 724)- que les preferències lèxiques de Curial e Güelfa no responen a estímuls tan poc personals com la llengua del dedicatari, o la d'un cercle de lectors que s'endevina ben restringit?». ${ }^{3}$ Tornant

1 Cito per l'edició d'Antoni Ferrando. Entre parèntesis hi poso el llibre, el capítol i la pàgina.

2 Com més torno a les pàgines del Curial e Güelfa més convençut estic que l'obra estava pensada, i escrita, per a un grup de coneguts, amics i gent de l'entorn de la cort napolitana d'Alfons el Magnànim (un grup, però, reduït, selecte i, alhora, preparat), capaç de sentir-se còmode amb aquest registre literari i de gaudir $-\mathrm{i}$, fins $\mathrm{i}$ tot, en ocasions, sentir-se còmplice- de les diverses situacions, bé de caire amorós, bé cavalleresc, o cultural, que van embastant el contingut i donant sentit als diferents episodis (pensem, també, per exemple, al públic al qui anava adreçat Lo somni de Bernat Metge).

3 Referint-se als possibles receptors de l'obra, afegeix que «(...) aquests poden tenir la clau explicativa d'un ambient cancelleresc on el destinatari de les lletres -i el dels llibres? - era el que determinava l'elecció del vehicle lingüístic». I Ferrando (2018: 77), en tractar de les preferències lèxiques emprades en la narració per l'anònim autor, exposa que aquesta «probablement fou concebuda per a ser llegida i comentada en veu alta entre els seus amics i col laboradors més pròxims».

SCRIP'TA, Revista internacional de literatura i cultura medieval i moderna, núm. 12/ desembre 2018/pp. 168-188 ISSN: 2340 - 4841 doi:10.7203/SCRIPTA.11.13671 
al lèxic, sembla que estiguéssim sentint Sèneca (2009: 258) quan a les seves Lletres a Lucili (40, 4) revelava que «(...) oratio incomposita esse debet et simplex»: en resum, la forma del discurs ha de ser natural i senzilla. Pel que fa a la llengua literària, descobrim que fuig dels excessos expressius, que no abusa de recursos literaris ni d'artificis; no és efectista, ans efectiva. ${ }^{4}$ En aquest sentit, podem apreciar suaus hipèrbatons: «volent scriure a vostra consolació e plaer, recitaré» (I.14, 59) «preciosos dons e grans heretats en què visquessen los donà» (I.46, 122), «fins ací havia fetes coses de recordança dignes» (II.49, 194); al literacions consonàntiques: «Era lo tendelló de vellut vellutat, burell e negre» (I.19, 68), o vocàliques i consonàntiques alhora: «brocat d'or molt ricós» (I.19, 68); poques, però belles perífrasis, acompanyades bé d'evocadores imatges: «vet que yo obre ja les mies orelles e aparell convinent loch a les tues paraules; ja lo meu cor tempra les plomes e s'aparella, ab los seus amaestrats dits, scriure-les en la mia memòria» (II.70, 212), respon la Güelfa a Festa per dir-li que vol escoltar-la amb molta atenció i conservar fermament en el record el que li digui; bé de personificacions, que augmenten l'efecte visual gràcies també a la sinestèsia: «Fugí la nit, e aquella stela que força e compel leix los hòmens a amar, mostrant la sua cara resplandent, tramés los seus raigs luminosos anunciant lo adveniment del dia» (III.99, 381). Sabem, però, per boca de l'autor, que l'estil canviarà en començar el tercer llibre, «lo qual és algun poquet pus intricat que ls altres primers» (III.0, 274). L'escriptor és plenament conscient que la matèria que passa a narrar a partir d'ara és més elevada i profunda, observació que tampoc no li passa desapercebuda al lector a mesura que s'endinsa en el teixit de l'argumentació, atès que se n'adona que es troba davant de noves propostes que no són les estrictament cavalleresques i sentimentals dels llibres anteriors; en conseqüència, no seran referides en un estil tan concís, ja que, ara, Curial es veurà immers en una realitat diferent: una nova dimensió humana i vital. Lògicament, aquest nou «rifacimento» de la prosa, més retòrica en determinats episodis, afecta el ritme de la lectura que, a més, requereix del lector un major esforç d'interpretació i una altra visió analítica davant les claus conceptuals que se li ofereixen. Sembla evident que en aquesta nova tessitura textual l'Anònim està pensant en un públic més preparat filològicament, capaç de copsar en detall les referències mitològiques i les «poètiques ficcions» que hi apareixen al llibre III, malgrat que, en una ocasió anterior -i sens dubte recorrent al tòpic de la falsa modèstia- hagi manifestat que no escriurà «daurant les letres» (...) «segons que és costuma dels scriptors» (II.101, 235); tot plegat, aquesta actitud ens parla del seu tarannà i de la seva voluntat de crear, si més no, un estil propi. En definitiva, això no fa sinó corroborar que té in mente un determinat tipus de lectors, davant dels quals vol mostrar-se més com un bon comunicador que no pas com un gran orador.

El registre lingüístic del Curial és la llengua vernacla, necessària i adient a l'entorn social en què

4 «El Curial és un producte literari d’una qualitat excepcional» (...) «és escrit en una prosa treballada, clara i elegant», opinen Lola Badia \& Jaume Torró (2011: 9, 106 i 111). Per la seva banda, Ferrando (2007: 20) ens diu que «(...) podem fruir d'una narració fascinant i amena, redactada no sols amb una exquisida consciència literària, sinó amb uns recursos lingüístics rics i variats, que l'autor ha treballat minuciosament» i ens fa veure com «El Curial és més que un text literari: el podem gaudir també com un text de cultura i fins de filologia» (2012: 83-84). Posteriorment (2018: 72), ens parlarà d'un autor «amb riques experiències plurilingüístiques i amb sòlids coneixements que avui en diríem filològics». 
s'escriu. Una llengua que, com a tret humanístic -i aquest havia estat també una de les aspiracions de Ciceró-, persegueix la difusió d'un sistema de valors, que reflexiona sobre l'ésser humà, on tenen cabuda, com apreciem en el cas del protagonista, el vici i la virtut: en aquest escenari, les paraules també col laboren en la consecució de la seva regeneració personal i s'hi posen al servei dels valors ètics de la comunitat; un missatge perseguit per l'autor, que sap on, com i quan ha de posar cada mot. ${ }^{5}$ Per això, i no ens ha de sorprendre, el text és un actor viu que fa de baula precisa en la transmissió d'aquests principis. Com assenyala Anton Espadaler (1984: 193 i 194), en parlar de la renovació estilística i temàtica que venia d'Itàlia, «L'estil s'adequa a la matèria $\mathrm{i}$ no es pot pensar una cosa sense l'altra». A banda d'això, constatem que el nostre escriptor sap modelar i enriquir la llengua quan li convé, sense ser presoner d'esquemes rígids ni d'una prosa exuberant i recarregada: un relat dinàmic $i$ ben treballat, enriquit, a més, per la presència de neologismes $i$ de llatinismes, adés en boca del narrador, adés en boca dels personatges, que es conjuminen a la perfecció amb frases i proverbis col loquials -alguns també d'origen llatí o bíblic-, i expressions italianes, apreses en la parla quotidiana o en les variades lectures del nostre escriptor. ${ }^{6}$ Una llengua que, al capdavall, li acaba resultant familiar al lector. Jaume Torró (2002: 23) destaca que un dels trets que vesteixen el Curial e Güelfa de modernitat rau en el fet de «saber elaborar una prosa culta, i fins llatinitzant, sense que es vegi gaire, sense que atempti el geni de la llengua, com dirien més tard». Prenc aquest detall de «llatinitzant», que ressalta Torró, per reforçar el valor de la llengua vulgar en què està escrit el Curial, que no defuig la influència de la llengua del Laci per vestir-se d'una major «elegància» -però que no n'abusa- en un moment en què l'ús del llatí com a mitjà de difusió de les idees humanístiques queda plenament justificat. Sembla clar que tornar els ulls vers l'Antiguitat per copsar aquells valor que feien de l'home un ésser vertaderament ple d'humanitas implicava recuperar de nou el bon llatí dels clàssics, especialment el de Ciceró, i retre culte a la retòrica com a base sustentadora de tota una nova filosofia de vida.

¿Desmereix, però, la nostra novel la pel fet de no haver estat escrita en llatí? De cap de les maneres, al meu entendre, atès que es tracta d'una obra, com he suggerit abans, pensada per a un determinat cercle d'amistats i de coneguts, poc o gens familiaritzats amb la llengua clàssica i, aquí, el romanç fa el seu paper: el de vehicle de comunicació, entre persones que usaven quotidianament el català, i de transmissió de molt sabers que ja s'havien estès en la llengua culta i als que molta gent, per la seva escassa o nul la formació en llatí, no tenia accés. «El món cavalleresc, a més a més -subratlla Espadaler (1984: 193) - (...) era més novel lable que mai. ¿I què millor per expressar la realitat que l'estil que a la vida real ja l'expressava: el tan digne vulgar cancelleresc?» Fixem-nos que dins del

5 Francisco Rico (2002: 45), en el seu ja clàssic llibre sobre el somni de l'humanisme, comenta que «Un arte, una ciencia, en efecto, no se transmite necesariamente como puro saber, sino también como modelo de vida o cuando menos como momento de una forma de vida.

6 D’això se n'ocupa Soler (2016: 1301-1319), i en dóna -i comenta prolixament- un bon grapat d'exemples. En un altre moment, Soler (2016: 1366) precisa que «L'anònim explora distintes possibilitats expressives, basant-se en el coneixement que té de tres lengües romàniques molt pròximes i integra diferents sensibilitats idiomàtiques». 
Jeroni Miguel Briongos. Curial e Güelfa, un nou món per a un nou cavaller: espais literaris en un entorn humanístic

propi humanisme, autors del Quattrocento com Leon Battista Alberti o Leonardo Bruni defensaven il volgare com a eina útil de relació social i com a forma de divulgar els ideals del nou moviment. Parem atenció, si no, al que diu Alberti (1980: 187) en el Proemi del tercer llibre de I libri della famiglia, tot just encomiant la llengua toscana que els seus conciutadans feien servir: «Piú tosto forse e' prudenti mi loderanno s'io, scrivendo in modo che ciascuno m'intenda, prima cerco giovare a molti che piacere a pochi, ché sai quanti siano pochissimi a questi dí e' litterati» ${ }^{7}$. I Bruni, en la seva Vita di Dante (1436), dirà que «ciascuna lingua ha sua perfezione e suo suono e suo parlare limato scientifico» (Russell 1985: 23). ${ }^{8}$ Badia i Margarit (1996: 171), en tractar de la rehabilitació de les llengües vulgars durant el segle XV, destaca que «Verdaderamente, no había contradicción entre dedicarse al latín o al romance. De esta forma todos iban preparándose a reconocer las dos opciones, sin que ello supusiera una jerarquía de valores». En un altre lloc (1999: 400), diu:

\begin{abstract}
Malgrat l'eufòria que suscitava el món clàssic, una llatinització al cent per cent era irrealitzable en els països que ja posseïen una cultura pròpia»; i afegeix que «Enfront dels humanistes durs, que no escrivien sinó en llatí, i que menyspreaven, ells sí, el conreu escrit de les llengües vulgars, existia una altra possibilitat: la de conjugar un ús digne i correcte del llatí i del romanç alhora.
\end{abstract}

A la Introducció d'aquest estudi (1999: 31), el doctor Badia mostra com els barcelonins Jeroni Pau i Pere Miquel Carbonell i els valencians Bernat Fenollar i Jaume Gassull compartien el mateix desig de dignificar la llengua vernacla (1999: 31). Al meu parer, l'humanisme va ser molt més que un bon grapat de textos escrits en un llatí acurat: va suposar una actitud davant la vida, una nova forma de pensar, una nova concepció de l'home sustentada en un programa educatiu; un ideal de civilització, en definitiva, on els clàssics eren un referent imprescindible, no tan sols pel model de llengua que calia emprar, sinó per la pedagogia que hi havia al darrere dels studia bumanitatis et litterarum als quals es referia Ciceró en el Pro Archia. ${ }^{9}$ Restringir, doncs, el terme humanisme només a aquelles obres escrites en llatí em sembla empobrir el mateix concepte i el sentit d'aquest moviment: ¿o tal volta el Canzoniere de Petrarca, la Fiammetta de Boccaccio, o les dues obres que acabo de mencionar d'Alberti i de Bruni han de quedar fora del concepte bumanisme només pel fet d'haver estat redactades en volgare? El cert és que les llengües vernacles, tant a la Corona d'Aragó

\footnotetext{
7 Tres línies més endavant, precisa: «Ben confesso quella antiqua latina lingua essere copiosa molto e ornatissima, ma non però veggo in che sia la nostra oggi toscana tanto d'averla in odio, che in essa qualunque benché ottima cosa scritta ci dispiaccia» (Bruni, 1980: 188).

8 Per examinar en detall el procés d'emancipació que va seguir il volgare a Itàlia, a l'ombra del llatí, vegeu l'estudi de Mclaughlin (1998: 269-294).

9 En aquest sentit, i a propòsit del concepte d'humanisme, Butinyà (2015: 199) comenta que «como fenómeno que afecta a toda la persona humana, repercute en el Arte, la Filosofía o la Ética, por lo que interesa a la historia cultural en general». I Rico (2002: 48) sosté que «el humanismo era, en suma, una cultura completa, todo un sistema de referencias, con un estilo de vida, y era en verdad un 'humanismo', un saber que acompañaba al hombre en las más variadas circunstancias».
} 
Jeroni Miguel Briongos. Curial e Güelfa, un nou món per a un nou cavaller: espais literaris en un entorn humanístic

com a la de Castella, van agafar una gran embranzida a recer dels textos que es difonien en llatí i, especialment, amb l'impuls de les traduccions, tant d'autors clàssics com d'escriptors italians del Quattrocento; encara més, van augmentar les seves capacitats d'expressió i van esdevenir instruments transmissors de continguts edificants i útils per a la instrucció dels lectors, com succeeix a la nostra novel la. Així, el Curial es fa ressò d'un dels lemes més preuats pels clàssics llatins i recuperat pels humanistes italians: docere et delectare. A més, com ja coneixem, molts dels antiqui que es prenen com a referent o model de comportament no entren en conflicte amb l'ortodòxia cristiana: Ciceró, o Sèneca, per exemple, són font inesgotable d'ensenyances molt profitoses per a qualsevol cristià. En aquest sentit, el nostre Anònim pren bona nota de totes aquestes possibilitats i exercita amb gran destresa l'art de l'aemulatio, és a dir, una imitatio que no segueix cegament el model, o que manlleva determinats fragments, sinó que, després d'una acurada lectura dels textos en llatí original, en català, en castellà, en italià o en francès, els fa passar pel garbell de la seva interpretació literària i els adapta, tant en el contingut com en la forma, a les necessitats del seu relat, amb elegància $i$ precisió. ${ }^{10}$ Aquesta forma d'escriure implica un respecte envers la font original, una participació en la propagació d'una cultura, d'uns valors i, fins i tot, d'una identitat, sense que la innovació, però, quedi exclosa. I aquest estil de fer és el que trobem al Curial e Güelfa.

\section{L'autor i el protagonista de la novel la: dos curials lletraferits $\mathrm{i}$ «scientifichs»}

Amb aquestes valoracions fins aquí fetes, he volgut fer palesa la preparació "scientífica" de l'Anònim, amb el valor que d'aquest terme se'ns dóna al llibre. L'autor no és un escriptor humanista stricto sensu, per descomptat, ni tampoc un scholasticus vir, però sí un cortesà, tal volta un noble cavaller familiaritzat amb l'administració de la cancelleria reial, o, per què no, un ambaixador, hoste en diferents corts europees, que parla diverses llengües i que, per raons del seu ofici, coneix el llatí; un gran lector lletraferit -un vir litterarum amantissimus, en poques paraules-, que si d'una cosa es lamenta, com ens revela, és de no haver-se dedicat a l'estudi des de la seva infantesa: «E si yo les hagués en la mia tendra edat servides, ara m socorrerien e ajudarien (...) mas yo no curí d'elles ne les coneguí» (III.0, 274). Malgrat això, estima el saber, en general, ha tingut un contacte amb l'estudi i està al dia de la cultura humanística en voga a Itàlia. ${ }^{11}$ Té també una molt bona formació literària:

10 A banda del ric estudi d'Espadaler (1984: 149-230) i del precís i detallat de Badia \& Torró (2011: 59-98), remeto, per a una visió més àmplia de les fonts que empra l'autor del Curial, als treballs de Butinyà (2001: 27-144) i de Soler (2016: 1818-2824 i 4752-4772). Respecte a aquesta imitatio, Butinyà (2001: 346), aferma que «el autor del Curial se nos muestra capaz de armonizar, de una manera ordenada, fuentes literarias muy diversas, del mundo nuevo y del viejo, del propio y del extraño. Asimilación que ejecuta con una gran naturalidad». I Badia \& Torró (2011: 105) consideren que «l’Anònim reescriu de dalt a baix els estímuls literaris presos de les fonts».

11 Soler (2016: 901-1163 i 4713-4747) ens ha deixat un retrat precís i molt bé documentat de qui pogué haver estat l'autor del Curial: es tracta de la figura d'Enyego d'Àvalos. Les tesis de Soler són atractives i suggerents i, al meu parer, suposen una aportació rellevant als esforços dels diferents estudiosos per esbrinar qui s'amaga darrere la figura de l'Anònim. 
Jeroni Miguel Briongos. Curial e Güelfa, un nou món per a un nou cavaller: espais literaris en un entorn humanístic

ha llegit les Cròniques medievals catalanes i els textos de la matèria cavalleresca de Bretanya; ha tractat els clàssics -els llatins, sobretot-, ja sigui mitjançant la lectura directa, o indirecta; posseeix un domini gens menyspreable de les fonts patrístiques i, per damunt de tot, té bona notícia dels autors italians més coneguts, els de «reverenda letradura»-els que coneixem com a pares de l'humanisme-, i també dels hereus d'aquests en el segle XV, continuadors de l'esmentat moviment cultural, molts dels quals contemporanis seus. És evident que demostra tenir una formació clàssica gens menyspreable, forjada, pel que sembla, en paral lel a les seves ocupacions professionals, quan el temps de lleure li permetia dedicar-se a l'otium negotiatum. Per això, no costa gens d'acomodar aquesta semblança a la imatge que ens dóna del protagonista de la novel la, quan ens confessa que Curial considerava «perdut aquell temps que sens estudi havia viscut» (III.79, 354). ${ }^{12}$ Un saber, el del nostre escriptor, que consolidà probablement primer a Montferrat i, després, a Nàpols, a la cúria d'Alfons el Magnànim. ${ }^{13}$ No hem de descartar que els dos primers llibres -o una bona part d'ells-, tant per les al lusions directes a la vida cortesana del marquesat, com per l'estil, l'autor els hagués pensat - $\mathrm{i}$ fins $\mathrm{i}$ tot redactat- durant una possible estada a la petita ciutat italiana, la durada de la qual no podem fixar amb precisió, mentre que el llibre III, més «intricat», més reflexiu i filosòfic, l'hauria pogut escriure a Nàpols si, com en general els estudiosos de la novel la reconeixen, era al servei del Magnànim. Nous continguts, doncs, i un nou estil per a un espai, la cort partenopea, on es respirava l'humanisme per tots els cantons, on homes con Antonio Beccadelli, el Panormita, Poggio Bracciolini, Bartolomeo Facio, Lorenzo Valla o Giovanni Pontano -per citar només alguns dels noms més rellevants- difonien el magisteri de les litterae humaniores. Aquest és l'ambient que, sens dubte, seduí l'Anònim, posseïdor d'un tarannà obert als nous corrents literaris del moment i a una mentalitat que estava canviant la concepció de molts valors socials i, especialment, la de l'esser humà, la interpretació del qual adquiria una nova dimensió a l'empara dels studia bumanitatis. ${ }^{14}$

Passant ara al nostre protagonista, Curial, sabem que els seus fets tenen lloc en temps del rei d'Aragó Pere el Gran, gairebé dos segles abans que s'escrigués la nostra novel la; de seguida, però, apreciem que la seva figura ja no respon a la del típic cavaller medieval, divulgada pels llibres de cavalleries, la missió de la qual era, pràcticament i exclusiva, anar a la guerra, lluitar contra altres cavallers, guanyar fama i aconseguir el favor d'una dama, sense sentir especial interès per l'estudi. Curial ens mostra la concreció d'un nou cavaller que, tot i conservant certs trets dels models difosos especialment pel

12 Vicent J. Escartí (2012: 270), tractant de la funció de l'escriptor i de l'escriptura literària, fa al lusió al «perfil de la cultura literària i llibrària de l'autor del Curiabı i assenyala que «aquesta seria equivalent a la del seu heroi o a la d'alguns dels seus personatges (...)».

13 Espadaler (1984: 50-58) argumenta que «l'autor del Curial bé podria haver tingut algun contacte amb la cultura que aleshores girava entorn de la cort monferratesa» i ens parla de l'ambient cultural i humanístic que hi havia durant el mandat de Giovanni IV (1445-1464), un governant «dedicat a la ciència, home obert a forasters, elegant $\mathrm{i}$ amb tots els atributs aparents d'un príncep de meitat del XV» (1984: 57).

14 Una visió més detallada d'aquest afany per l'amor a l'estudi i a la cultura que es vivia a la cort del Magnànim pot trobar-se a Jeroni Miguel (2004) 
Jeroni Miguel Briongos. Curial e Güelfa, un nou món per a un nou cavaller: espais literaris en un entorn humanístic

roman courtois i per alguns llibres sobre vides de coneguts homes d'armes (pensem, per exemple, a Jacques de Lalaing, a Jehan de Maingre, conegut com a Boucicaut, o a Pero Niño, ), va més enllà de ser un reflex literari d'aquests i ofereix uns valors de comportament personal nascuts a recer de les circumstàncies històric-culturals en què viu el seu creador: les de l'humanisme, a Itàlia, la filosofia del qual entén que la formació d'un cavaller no és completa si la fortitudo no va acompanyada de la sapientia. ${ }^{15}$ En aquest sentit, Jordi Galves (2007: 18-19) comenta:

\begin{abstract}
Els cavallers ho son (...) per l'exercici de les armes, però també perquè poden exhibir unes formes civilitzades, cultes, perquè poden exhibir una formació distingida. Aquesta és la gran preocupació del moment, la de la batalla contra la ignorància (...) ja sigui refermant i reelaborant les conviccions cavalleresques més tradicionals o, com a molts indrets d'Itàlia, adoptant les noves solucions dels humanistes, que clamen per l'estudi acurat de la llengua i la literatura llatines.
\end{abstract}

Sabem, per altra banda, que aquesta actitud no era comú en el món de la cavalleria: pel que fa a la Península ibèrica, per exemple, la noblesa, en general, era refractària a l'estudi, i els homes d'armes que s'interessaven pel llibres eren una minoria, malgrat que alguns d'ells -també s'ha de dirarribaren a formar importants biblioteques. Així, no va faltar qui veiés la poca utilitat del binomi armes-lletres en la formació d'un cavaller: reveladores són les paraules que a don Pero Niño, el protagonista del Victorial de Gutierre Díaz de Games, li dedica el seu preceptor, quan li recorda que «el que á de aprender a usar arte de caballería, no conviene despender luengo tiempo en escuela de letras» (Díaz de Games 2014: 91). Tanmateix, hi va haver excepcions molt honroses: pel que fa a la Corona de Castella, Enrique de Villena, un dels més fervents defensors del saber d'aquest temps, en els Dotze treballs d'Hèrcules ens presenta l'heroi pagà com a model de cavaller que integra, en perfecta harmonia, les armes i les lletres; en el capítol quart, posa èmfasi en la conveniència de l'estudi per als homes que es dediquen a la milícia: «Esto fue escripto a perpetual memoria del dicho Ércules por los istoriales, a fin que los cavalleros non menospreçiasen darse a aprender a las e las sçiençias, segunt aquéste fizo, ca por eso non perderán el uso de las armas, contra la opinión de muchos bivientes en aqueste tiempo o modernos, que afirman abaste al cavallero saber leer e escrivir» (Villena 1994: 34). I figures com la del marquès de Santillana, ens apropen a la de Curial. ${ }^{16}$ A la Corona d'Aragó tampoc no van faltar cavallers amants dels llibres: Jordi de Sant Jordi, Ausiàs Marc, Mossèn Lluís Gras, el Príncep de Viana, Joanot Martorell, i d’altres, en són

15 Cingolani (1994: 149), fent esment de les diferències, com a cavallers, entre Curial i Tirant, posa en relleu que «Curial è un uomo costretto alla ricerca della propria perfezione umana e persegue un diverso modello, quello del cavaliere letterato». I Butinyà (2001: 177) afegeix: «Estamos en una etapa de valoración culturalista y no rupturisa hacia el pasado. La via que da la solución, ya propuesta por Petrarca, y que habrá de saber conjugar este tipo de caballero humanista, de armas y letras, es la del estudio».

16 Ha esdevingut ja clàssica la coneguda expressió d’Íñigo López de Mendoza, marquès de Santillana, recollida en els seus Proverbios: «La sçiençia non enbota el fierro de la lança ni faze floxa la espada en la mano del cavallero» (López de Mendoza 2003: 370). 
uns quants. ${ }^{17}$ És la nova imatge, en definitiva, d'una noblesa conscient que l'accés a la cultura la prepararà millor per als nous reptes d'una societat en constant transformació. I aquesta és la idea que ens vol transmetre l'Anònim en oferir-nos un prototip de cavaller, Curial, que podem encabir dins del que es coneix com a cavalleria humanística. ${ }^{18}$ Els temps han canviat i també les actituds respecte a la centúria anterior; ara, nobles i cavallers entenen que si volen mantenir la seva força com a estament i no perdre cotes de domini social i polític han d'apropar-se al món del saber. ${ }^{19} \mathrm{El}$ nostre protagonista ho fa de bon començament, només arribar a casa del Marquès, a Montferrat: «(...) per no perdre temps, aprés gramàtica, lògica, rectòrica e philosophia, e fonch valent home en aquestes sciències, e així mateix poeta molt gran, en tant que en moltes partides, sabent-se la sua sciència, devench molt famós e era tengut en gran estima» (I.3, 46). Fixem-nos en aquest «per no perdre temps», que ens recorda el que, com he comentat abans, en ha confessat l'autor respecte al fet que en els seus primers anys no s'havia dedicat a l'estudi. En conseqüència, ara, Curial no ha de perdre el temps; tant és així, que encara no ha fet les primeres passes en el domini de les armes, per esdevenir cavaller, $\mathrm{i}$ ja és admirat a la cort per la seva ciència. Curiosament, aquesta actitud serà una constant al llarg de la seva trajectòria vital i humana. Curial sap que ha d'harmonitzar la fortitudo amb la sapientia i, pel que podem llegir, ambdues qualitats l'acompanyen al llarg dels seus primers anys de gestes cavalleresques: serà ni més ni menys el rei de França qui, davant les acusacions dels dos vells envejosos, ens ho recordarà: «Car és tan diligent, que no pert temps, car, com armes se fan en qualsevol manera, ell és dels primers e se'n porta la honor (...); e partit d'aquí, no lexa l'estudi, ans tracta tan reverencialment los libres, que tots quants lo conexen ho han a gran maravella» (II.116, 247). ${ }^{20}$ Apol lo, a més, en la primera visió que té Curial, «presos alguns rams dels arbres a ell consagrats» el corona i el reconeix com a «Millor e pus valent entre los cavallers, e major de tots los poetes e oradors qui vuy són» i, en paraules ara del narrador, «Comunicà-li tota la sapiència de la sua deïtat, en manera que Curial fonch informat així de les virtuts e estrenuïtats dels cavallers, com

17 Podem seguir les petges d'una àmplia nòmina d'homes d'armes, lligats a l'entorn del Magnànim, molts d'ells amants de les lletres, a Soler (2016: 484-666). A Itàlia, però, la manca d’uns mínims fonaments culturals era semblant a la que hem vist a Castella: una cosa era el que deien els viri litterati, respecte a la necessitat de què els nobles es formessin mitjançant l'estudi, i una altra la realitat. «(...) es compten quasi amb els dits d'una mà -revela Soler (2016: 483)- els nobles italians de la segona meitat del segle XV (Jacopo de Montemagno, Angilberto del Balzo, Girolamo Sanseverino duc de Melfi, Antonello Petrucci i Lanzalao de Pisinis) que manifestaven algun interès per la cultura escrita».

18 Butinyà (2012: 203) assenyala que «si hi ha un extrem al Curial ho és decantat cap a l'estudi, on sí que es manifesta l'autor prou radical, cosa que fa veure un tarannà que oposa la societat civil a la castrense de temps passats i dóna pas a la cavalleria humanística».

19 Pocs anys després que s'escrigués la nostra novel la, el barceloní Francesc Alegre, en el seu pròleg a la traducció de les Metamorfosis d'Ovidi, deixava constància que la dedicació a les lletres obria als cavallers el camí cap a l'ascens social (vegeu Gonzàlvez 2000: 873).

20 De la importància que l'Anònim atorga al concepte de l'estudi, com a element imprescindible en la formació íntegra del cavaller, en tenim referència al cap d'unes línees, quan el monarca, que continua destacant els valors humans de Curial en presència dels vells envejosos, hi insisteix novament: «E així, no curets d'aquestes coses, car la costuma de la cavalleria e de la sciència és tal, que avancen los hòmens de pobre estat e ls fan grans senyors» (II.116, 248). 
Jeroni Miguel Briongos. Curial e Güelfa, un nou món per a un nou cavaller: espais literaris en un entorn humanístic

de la composició e ordinació dels libres» (III.34, 309). ${ }^{21}$ D'aquesta manera, podem entendre -tot i que com a imatge premonitòria, atès que ha estat el resultat d'una visió- que, durant el captiveri que temps després passa a Tunis, expliqui a Càmar passatges de l'Eneida que la jove no comprèn. Procés, doncs, tancat: sigui en l'afirmació del rei de França, sigui en el veredicte d'Apol lo, Curial ha sabut harmonitzar en la seva persona la fortitudo i la sapientia. Sabem, però, que, més endavant, el nostre protagonista portarà les seves passes cap al vici i la luxúria i s'allunyarà de la virtut i del fonament on se sustentava aquesta: l'estudi. Com recordava Ennea Silvio Piccolomini (2002: 128) en el De liberorum educatione, «Postquam exclusae sunt litterae, omnes elanguisse virtutes». Tanmateix, el jove cavaller es redreçarà i, prenent consciència - gràcies a la visió en què se li apareix Bacus- del camí equivocat pel que ha errat durant un temps, tornarà als llibres: «(...) per què tantost, lo jorn següent, féu cercar libres en totes les facultats, e tornà al studi, segons havia acostumat, tenint per perdut aquell temps que sens studi havia viscut» (III.79, 354). Parlaré de nou de la importància d'aquest aspecte en tractar del creixement intel lectual i personal del protagonista, al punt 4 d'aquest estudi. Fins a aquí, he intentat dibuixar les inquietuds que, envers el saber, comparteixen tant l'autor com Curial i perfilar els contorns dels paisatges culturals que els envolten: un trajecte vital, un itinerari, que mostren com l'essència de l'ésser humà no pot assolir la seva expressió més pregona i íntima -al capdavall, la virtus defensada pels clàssics- lluny del magisteri de les lletres.

\section{Curial davant la cruilla}

Com veiem al llibre III, Curial ha hagut de passar un captiveri a Tunis, tant físic com emocional. Són set anys de solitud, tot i la companyia de Galceran de Madiona, que li serveixen, a banda de reflexió íntima i personal, per no caure davant les proposicions amoroses de Càmar i no repetir els errors que havia comès amb Làquesis. Sembla que el jove cavaller ha tingut presents les paraules d'admonició que, en una ocasió anterior, a les acaballes del llibre II, li dirigeix Melchior de Pandó: «Obrits los ulls de l'enteniment, e, si havets errat, esmenats-vos, e no errets altra vegada, car aquesta error seria pijor que la primera» (II.136, 261). Curial, ara, es manté fidel a la Güelfa i, per aquesta raó, quan torna a Montferrat, espera el seu perdó i la seva correspondència amorosa. Tanmateix, com sabem, la resposta de Güelfa, determinada a defensar el seu vot, com li confessa a l'abadessa, és negativa i el rebutja. Curial, en conseqüència, abandona el marquesat i, a França, «se donà a viure mollament e laciva (...) no recordant-se ésser cavaller ne home de sciència; ans així la disciplina militar, com la vigília del studi, mes totalment en oblit, e en menjars, convits e festes, vestirs e altres

\footnotetext{
21 Segons Soler (2016: 1861-1862), aquestes paraules d'Apol lo reconeixent Curial com a «major de tots els poetes e oradors que vull són» remeten «a l'horitzó que l'optimisme humanista de la Florència del 1400-1440 prometia a aquells que s'endinsaren per la treballosa senda dels studia bumanitatis traçada per homes com Petrarca, Salutati i Bruni. Fins i tot, els cavallers i els prínceps, si s'esforçaven, aconseguirien el guardó d'esdevenir uns homes virtuosos i bumanissimi sense haver d'abandonar per això la vida activa».
} 
Jeroni Miguel Briongos. Curial e Güelfa, un nou món per a un nou cavaller: espais literaris en un entorn humanístic

vanitats, e n los actes de Venus despenia totalment lo temps» (III.78, 351-352) 22. Què ha succeït? Doncs que el jove cavaller, en lloc de continuar estudiant i de guanyar fama i mèrits mitjançant noves gestes cavalleresques per tal de recuperar el favor de la Güelfa, s'enfonsa en el vici: erra el camí. Davant la disjuntiva que la vida li ofereix, pren la via equivocada. Aquí, l'Anònim, implícitament, està rememorant l'episodi d'Hèrcules davant la cruilla, que va gaudir d'una gran acceptació literària des de l'Antiguitat i que ara agafa nova embranzida en mans d'humanistes italians com Colucio Salutati o Pier Paolo Vergerio. La imatge del bivium es remunta als Memorabilia (II, I, 21-22) de Xenofont, qui pren la font de Pròdic de Ceos. Més tard, Ciceró contribuirà a difondre el seu contingut: en el De officiis, I, XXXIII, ens presenta Hèrcules meditant sobre la via que agafarà, si la del vici o la de la virtut, tot i que, finalment, no podem arribar a esbrinar quina tria. Curiosament, el mite va tenir bona acollida entre els pares de l'Església, com en donen fe Lactanci i Sant Jeroni. Com ha destacat Francisco Rico (1974: 304),

En la historia del motivo (...) Lactancio desempeña un papel destacadísimo. Efectivamente, en las Divinae institutiones se explica que la vida humana debe marchar por una de dos vías: «una, quae in caelum ferat; altera, quae ad inferos deprimat». La una es la vía de las virtudes, ardua y en cuesta, pero coronada por la mejor recompensa; la otra es la vía de los vicios, fácil y amena, pero conducente al precipicio. Todo hombre, «cum primae adulescentiae limen adtigerit», arriba a la encrucijada: como la Y, 'el camino se escinde en dos partes', y el adolescente ha de elegir entre la «frugalitas» y la «luxuria» (...).

Sant Basili el Gran, en concret, en la seva al locució adreçada als joves, De libris gentilium legendis -un manifest en defensa dels studia humanitatis, que va tenir una gran difusió al llarg del segle XV gràcies a la versió que de l'obra en va fer Leonardo Bruni-, suposà un referent literari cabdal per a la posteritat: Hèrcules, en arribar a l'adolescència, moment en què els joves han de decidir cap a on orientaran la seva vida, si envers la virtut o envers el vici, dubta quin camí prendrà. Llavors, se li apareixen dues dones, la Virtut i la Maldat, que s'apropen a ell; aquesta última embelleix el seu rostre amb afaits i intenta atreure'l amb gestos voluptuosos, prometent-li plaers encara més grans; la primera, al contrari, amb les carns seques i l'esguard adust, no li ofereix una vida dissoluta i de llibertinatge, ans d'innombrables esforços i perills, tant per terra com per mar. Aleshores, l'heroi pagà segueix aquesta última, convertint-se, així, en referent i model de futures interpretacions. ${ }^{23}$ L'impulsor, però, entre els humanistes va ser Petrarca: tant al Secretum com al De vita solitaria, se'n fa ressò d'aquest tópos, i l'heroi grec esdevindrà paradigma de l'home que, amb ferma voluntat, és capaç de dominar les seves passions. Recordem, de pas, que a la Península Ibèrica Enrique de

22 Pel que fa a l’abandó dels estudis per part de Curial i la intervenció de Bacus en la regeneració personal del jove cavaller, vegeu Butinyà (2001: 176-183)

23 Per seguir en detall la tradició de l'episodi i entendre la repercussió que va tenir entre els humanistes italians, és imprescindible el treball de Guido Cappelli (2000). Vegeu, a més, amb referències interpretatives aplicades a la nostra novel la, els treballs de Miguel (2009: 45-49) i de Soler (2016: 1560-1562, 2340-2342 i 3780-3784). 
Jeroni Miguel Briongos. Curial e Güelfa, un nou món per a un nou cavaller: espais literaris en un entorn humanístic

Villena escriu els Dotże treballs d'Hèrcules, llibre que coneixia bé l'autor de la nostra novel la, i, a mitjans del segle XV, també Juan de Lucena, al seu Diálogo sobre la vida feliz, col laborarà a difondre el mite. És palès que, a l'època en què l'Anònim escriu, tant el bivium com la Y pitagòrica eren prou coneguts i que Hèrcules personificava un exemple per treure-hi ensenyances morals. Com assenyala Cappelli (2000: 512-513),

La reviviscencia del mito de Hércules en la encrucijada (...) es un indicio de un nuevo gusto, una seña de identidad 'humanista' más que el humanismo (...) iba difundiendo en forma de tópicos, mitos, consignas (...) Todo ello fue una aportación genuina del humanismo italiano, a partir de Petrarca, y a lo largo de todo el siglo XV, la época que, con diferencia, lleva más honda que cualquier otra la huella de la cultura italiana.

Tornant novament a Curial, podem dir que, durant aquest període de temps que ha viscut lliurat a la luxúria i allunyat dels estudis, ha estat com a mort humanament i moralment. S'ha oblidat, en definitiva, d'ell mateix, de manera semblant a com els homes, admirats per les altes muntanyes, els grans rius, per la immensitat de l'oceà i pels girs dels astres, se n'obliden d'ells mateixos, com recordava Sant Agustí a les Confessions i que Petrarca (1977: 32) recull en el seus Familiari rerum libri: «Et eunt homines admirari alta montium et ingentes fluctus maris et latissimos lapsus fluminum et occeani ambitum et giros siderum, et relinquunt se ipsos». Aquesta mort simbòlica del nostre cavaller ens remet a allò que Sèneca (1974: 576) deia al seu estimadíssim Lucili en la lletra 82, «Otium sine literis mors est, et hominis vivi sepultura» i ens porta, alhora, a la del protagonista del Secretum de Petrarca, Francesco: al llibre segon, la vida recta i modèlica que havia dut el jove pateix un daltabaix i es veu arrossegat al vici; aleshores, Sant Agustí, el seu interlocutor, li recorda que aquest capteniment l'impedeix veure la glòria divina. ${ }^{24}$ De la mateixa manera, Curial es veu privat de la «glòria» de la Güelfa i ha de passar pel «purgatori» que li recordà Melchior de Pandó anteriorment, a principi del llibre III, quan el cavaller, davant la negativa de la Güelfa a respondre a les seves paraules i a veure'l, creu que ja ha perdut les «claus de paradís»: «Emperò, cas que vullats que aquest sia paraýs, siats cert que en aquest, ni en aquell, no 's pot entrar sinó passant primer per purgatori» (II.143, 266). I així va continuar, purgant els seus errors i les seves penes, fins que «Aquell déu que los gentils apellaven déu de sciència, ço és, Baco (...), a Curial se mostrà» (III.79, 352). En aquesta nova visió del protagonista, Bacus s'adreça personalment a ell per recordar-li com, després que hagués deixat l'estudi i hagués caigut en el món de la lascívia, se n’havia oblidat de les set arts lliberals que ara han anat apareixent, una a una, davant d'ell; per això li prega que «torns al studi e vulles honrar aquestes dees que t'an honrat e favorit, e lexa aquexa vida, qui porte l'ome a fretura, vituperi e desonor; e la sciència, que és don divinal e eternal, no la vulles cambiar per la brutura et sutzura, terrenal e temporal» (III.79, 354) Curial, doncs, té ara l'ocasió per tornar al camí

24 En el De vita solitaria, Petrarca (1992: 54) ens deixa una retrat significatiu de com aquest tipus de vida és semblant a un exili, a una presó i a una tortura; però ens ensenya també que, si tornem a les lletres, aquesta solitud esdevé pàtria, llibertat i delectació: «Equidem solitudo sine literis exilium est, carcer, eculeus; adhibe literas, patria est, libertas, delectatio». Veiem aquí que, aplicat al cas de Curial, la conclusió és clara: el jove cavaller, captiu d'aquesta vida dissoluta, viu en una presó individual i exiliat de la seva estimada. 
Jeroni Miguel Briongos. Curial e Güelfa, un nou món per a un nou cavaller: espais literaris en un entorn humanístic

recte i agafar la via de la virtut, com havia fet Hèrcules, que també se li apareix en aquesta visió. Com indica Butinyà (2001: 349),

\begin{abstract}
La amonestación principal de Baco, la primacía de lo intelectual sobre lo material, (...) no es un mensaje basado en el desengaño o el miedo, sino en la valoración más positiva y vitalista del estudio. ¿No era el mensaje específico que podía entender un humanista de aquel primer momento y el único que le pudiera hacer rectificar?
\end{abstract}

La presència de l'heroi pagà és significativa ja que suposa un referent per a ell i un exemple de comportament que coneix: ${ }^{25}$ curiosament, Curial, que havia estat el cavaller «pus fort e valent de tots», com se'ns recorda al llarg de la novel la, ara, davant la presència d'Hèrcules «hach molt gran por» (III.79, 353) i, espaordit, ha de buscar l'empara que Bacus generosament li ofereix. ${ }^{26}$ L'escena ens dibuixa un Curial acovardit, empetitit, el revers moral i personal del que havia estat; ha tocat fons i no té altre camí que redreçar la seva vida si, després del purgatori que ha viscut, vol assolir la glòria: per tant, en aquest moments, davant del bivium en què es troba, $\mathrm{i}$ tot recordant les paraules de Bacus, no té una altra alternativa que agafar el camí de la dreta, és a dir, el de la virtus, com havia fet Hèrcules. D’aquesta manera, «lo jorn següent féu cercar libres en totes les facultats, e tornà al estudi, segons havia acostumat, tenint per perdut aquell temps que sens estudi havia viscut» (III.79, 354). «L'aprenentatge, la investigació filosoficomoral de tot allò que pot fer l'home "poderós i savi”, virtuós i apartat dels vicis -precisa Soler (2016: 2396)-, esdevingué una de les consignes del moviment humanista, des de Petrarca a Bruni, passant per Salutati. I és el que explica l'afany de Curial per buscar llibres (...)».

\title{
4. El creixement intel lectual i humà de Curial: un viatge cap a la interioritat
}

L'estudi, en conseqüència, portarà Curial a la regeneració, li permetrà sortir de l'exili interior en què ha viscut i podrà recuperar el camí que el durà a la consecució d'una vida íntegra. En aquests moments, tenen encara més validesa les paraules que Melchior de Pandó diu al seu pupil en acabar el llibre II: «Altra és la via per la qual has a caminar, car la que tens no porta l'ome sinó a abatiment. Regoneix-te bé, e venç a tu mateix mentre has temps» (II.145, 267), paraules que el propi autor recorda novament al protagonista als inicis del llibre III: «Recognosce te ipsum ne te extollas» (III.0, 273), un tópos clàssic que Boeci s'encarregà de difondre a la seva Consolatio philosophiae, quan adduia que qui vulgui saber - reflexionant profundament- on es troba la veritat, ha de girar envers ell mateix la llum de l'esguard interior per no errar el camí. ${ }^{27}$ Posteriorment, Colluccio Salutati, en

25 Sobre la figura d'Hèrcules i el seu paper com a model per a Curial, vegeu Gonzàlvez (2004: 42-46). A més, Badia (1987: 288-290).

26 Per a la interpretació d'aquesta visió on Bacus s’apareix al nostre cavaller, vegeu Badia (1987: 265-292).

27 «Quisquis profunda mente vestigat verum / cupitque nullis ille deviis falli, / in se revolvat intimi lucem visus» (Boeci 2010: 232). Per la seva banda, Miralles (2012: 450) assenyala que «Aquest reconeixement no és només el conéixer 
Jeroni Miguel Briongos. Curial e Güelfa, un nou món per a un nou cavaller: espais literaris en un entorn humanístic

el seu De saeculo et religione, i en consonància amb els postulats de l'humanisme, defensava la filosofia com a escola de vida que havia d'ensenyar les persones a ser conscients de la seva realitat i a meditar constantment "sulla condizione umana e sulla sorte dell'uomo, sulla sua condotta, sulle forme della sua vita» (Garin 1978: 37). Curial, ara, ha après la lliçó, ha madurat: després d'haver passat moltes proves i d'haver esmerçat molts esforços, arriba a la reflexió personal, de forma que abandona la supèrbia i pren el saber com a mestre de vida; només així, amb aquest «agere et intelligere»-que propugnava Manetti- es veu lliure de la persecució de la Fortuna i pot redreçar la seva vida. ${ }^{28}$ Curial s'ha regenerat i s'ha retrobat íntimament, podríem dir, com a part d'aquest procés de recuperació personal que apreciem al llarg de tot el llibre. Cal afegir-hi que l'humanisme italià no va ser mai aliè a les inquietuds per cercar noves sendes que duguessin a l'exercici del coneixement de l'home i de la vida interior, independentment del sentiment religiós. Un cop més, Petrarca va ser pioner i les seves petges es troben en bona part de les pàgines que durant el Quattrocento es van escriure al respecte. Ell, concretament, s'encarregà de difondre la idea agustiniana de l'bomo interior: Sant Agustí (De magistro, I, 2) havia insistit que Déu no el podem trobar "per articulatum sonum», ans resseguint els camins que solquen l'esperit, el que ell anomena homo interior, font que el bisbe d'Hipona troba a Sant Pau. El pare de l'Església tornarà a insistir en aquest concepte en altres escrits, com en el De vera religione, XXXIX, 72, per citar només un exemple d'aquesta philosophia Christi; aquí, posa l'accent en la necessitat que dirigim les passes cap a les estances del nostre interior: «in te ipsum redi; in interiore homine habitat veritas». No debades, Eugenio Garin (1978: 29) explica que «L'appello all'interiorità che Petrarca rinnova in termini agostiniani non suona isolamento, ma esaltazione del mondo umano, del mondo dei valori e dell'azione, del linguaggio e della società (...)». ${ }^{29}$ La presència de Sant Agustí a la nostra novel la també l'ha feta palesa Abel Soler (2016: 2308-2309), qui, al respecte, aferma:

La purgació moral a què l'autor del Curial sotmet el cavaller llombard estarà dirigida per aquest «prohom» savi i lector d'Agustí. Melchior esdevé un mentor ideal per a l'adolescent. El «procés de la vida del nostre cavaller», com l'anomena l'escriptor (...), té molt a veure amb el plantejament teològic d'Agustí, però sotmès a una revisió en clau paganitzant o profana, seguint la tendència evolutiva del pensament neoplatònic de l'humanisme italià.

o reconèixer Curial per part dels altres, l'amagar-se ell o no, per silenci o fins a l'engany (...) sinó també l'antic precepte del déu de Delfos, l'autoconeixement o retrobament d'un mateix; a través de les proves, de les vicissituds de la vida».

28 Com recorda Petrarca en diferents escrits, si volem deslliurar-nos de la Fortuna, hem de dominar les passions. Butinyà (2004: 46) destaca que «el héroe de esta novela, en su enfrentamiento a los sucesos, logra conseguir la virtud según la dinámica humanista, en la que el hombre domina a la Fortuna, según se ha anunciado desde el prólogo con frase de Petrarca». I pel que fa al paper primordial que té l'estudi com a camí per vèncer la Fortuna, Torró (2002: 37) extreu una clara conclusió: «la fortuna no té cap poder sobre l’home savi». Vegeu, també, Soler (2016: 1999, 2002-2003, 2186 2249-2250 i 2482-2489).

29 Per la seva banda, Galves (2007: 67) ressalta que si Curial esdevé savi és perquè «penetra en la veritat de la realitat, afermant-se en la llibertat, a la recerca d'una plena autorealització de si mateix».

SCRIPTA, Revista internacional de literatura i cultura medieval i moderna, núm. 12/ desembre 2018/pp. 168-188 ISSN: 2340 - 4841 doi:10.7203/SCRIPTA.11.13671 
Jeroni Miguel Briongos. Curial e Güelfa, un nou món per a un nou cavaller: espais literaris en un entorn humanístic

Aquestes són les estances que, implícitament, ha hagut de seguir Curial per poder escoltar la seva veu interior, la de la reflexió, la de la valoració del sentit de la seva vida, la veu de la veritat, que el reconeix com a ésser fràgil, amb tots els seus vicis i les seves virtuts, però que el portarà a la regeneració humana i moral i a l'acció, com a trajecte vital, no a pagar les seves culpes pels errors comesos, que era el concepte medieval d'expiació. ${ }^{30}$ Insisteixo que aquest aspecte de la recerca de l'home interior, concepte que formava part de la pràctica d'un cristianisme intimista i proper als Evangelis, era una de les preocupacions més pregones dels humanistes: Lorenzo Valla, en concret, va acollir en els seus escrits, al costat de qüestions estrictament filològiques, la necessitat de la renovació interior de l'home: «non exterior homo, sed interior placet Deo» (Rico 2002: 126-127). ${ }^{31}$

Com podem apreciar tan bon punt comencem a llegir la novel la, els orígens de Curial han estat humils, semblants, per altra banda, als de Petrarca, tal con l'Aretí ens recordava en el seu Posteritati: «Honestis parentibus, florentinis origine, fortuna mediocri et -ut uerum fatear- ad inopiam urgente» (Petrarca 2007: 28); també sabem que els seus pares han estat honorables -la seva mare es diu Honorada-, però alhora se'ns fa palès que el jove fadrí que acaba d'arribar a la cort del marquès de Montferrat no posseeix la noblesa ex sanguine heretada dels pares. Aquesta és una circumstància de la qual la Güelfa n'és molt conscient; tant, que, a penes sent el punyiment amorós envers Curial, «no havent esguart a claredat de sanch ne a multitut de riqueses», però «veent-lo mol gentil [de] la persona, e assats gentil de cor, e molt savi segons la sua edat (...) pres càrrech de ajudar-lo e, a despit de la pobredat, fer-lo home» (I.4, 46 i I.5, 47). La jove veu, al capdavall, que Curial haurà d'emprendre un camí llarg, el de la virtut, per assolir la noblesa: ella l'ajudarà, donant-li els béns materials i les riqueses que necessiti; per la seva banda, ell haurà de posar-hi, en aquest futur trajecte de creixement personal, l'esforç, la voluntat i guanyar-se pels seus propis mèrits el dret a esdevenir en un futur el seu marit. A més, com sabem, el captiveri a Tunis i el temps que passa lliurat a la vida dels plaers i de la luxúria suposarà una gran lliçó humana que ajudarà el nostre protagonista a reconèixer en la virtus - un dels valor humans més preuats pels clàssics llatins i que arrelà amb força entre els humanistes italians- l'única via que el podia dur a la consecució de la integritat personal i, alhora, del perdó de la Güelfa. Així, el tópos estoic, que s’avenia a la perfecció amb la filosofia humana del cristianisme, participa, en el nostre cas, en la creació d'un nou cavaller. ${ }^{32}$ En

30 Butinyà (2001: 138) matisa que «a Curial no le pasan las desgracias como castigo sino como ocasión de reparación»; i, aquí mateix, recorda que «El gran objetivo del III libro (...) tiene un segundo objetivo, de repercusión, pero que es la finalidad prioritaria de la obra: la conversión de Curial» (2001: 356).

31 Cappelli (2007: 266) para també atenció en aquesta preocupació de Valla i s’hi fixa en el De professione religiosorum: «De ahí $\square$ comenta $\square$ que la auténtica religión se viva, para Valla, en el foro interior, mucho más que en virtud del estado seglar o eclesiástico».

32 «El autor manifiesta un concepto estoico de la virtud -subratlla Butinyà (2001: 79)-, ya que la define como la fuerza interior que nos hace libres, nota que rastreamos claramente en Séneca. Y anotemos que no se habla de mal y bien, sino de la fuerza para seguir el camino de la verdadera libertad; es decir, para el dominio de los vicios». 
Jeroni Miguel Briongos. Curial e Güelfa, un nou món per a un nou cavaller: espais literaris en un entorn humanístic

la voluntat de l'Anònim hi és la ferma convicció de donar un paper molt rellevant a la consecució de la noblesa mitjançant el camí de la virtut: de fet, tot el que succeeix al llarg de la novel la gira al voltant de l'assoliment d'aquesta fita. No serà la primera ni l'única vegada en què l'autor hi tornarà a insistir en aquest aspecte. Aquí només faré esment d'un altra ocasió en què el binomi virtutnoblesa s'expressa en perfecta simbiosi: correspon al moment en què Làquesis comunica a la seva mare la seva voluntat de casar-se amb Curial; llavors, la seva progenitora li diu: « (...) tu ames home qui no és covinent a la tua noblesa» (II.85, 222), instant en què la jove li respon plena de decisió i convenciment: «نrecordats-vos, senyora, de les paraules que dix Guismunda a Tancredi, son pare, sobre lo fet de Guiscart, e de la descripció de noblesa?» (II.86, 223). La referència a l'episodi que es recull al Decameró, a banda de reforçar els arguments de la donzella, té una paper significatiu:

\begin{abstract}
El pensament amorós de l'autor del Curial-explica Espadaler (1984: 236) - es resumeix en la història de Guiscardo e Ghismonda: la que segons Làquesis legitima l'amor entre persones d'estament desigual. Les virtuts de Curial no han de ser solament militars. La idea clau és la de noblesa. Una categoria intricada. Segons Làquesis, Curial és «gentil home pobre», però «la gentilesa ja la té». ${ }^{33}$
\end{abstract}

Vull ressaltar que, a la Itàlia del Quattrocento, el debat sobre la importància de la noblesa assolida mitjançant la virtus, segons el model que es volia imitar dels avantpassats romans, formava part de la interpretació de la vida i de la filosofia de l'humanisme. ${ }^{34}$ D'aquesta manera, des de Buonaccorso da Montemagno a Angelo Poliziano, els exemples són nombrosos i eloqüents. Basti citar, del primer, el seu De nobilitate (ca. 1420): aquí, l'escriptor de Pistoia posa èmfasi en el fet que la noblesa no la hi donen els béns heretats, sinó la virtut de cada persona: «Constat igitur ex sola animi virtute veram nobilitatem defluere» (Montemagno 1976: 142). En termes similars es pronunciava Poggio Bracciolini, el 1440, en una obra titulada també De nobilitate, i, ja a les acaballes del segle, Cristoforo Landino defensava el concepte de noblesa derivada de la virtut «e non da diritto ereditario» (Garin 1978: 58). Estem, doncs, davant d'una actitud que reacciona contra la tradició medieval que posava en el llinatge i en la possessió de riqueses el fonament de la nobilitas. Lletrats, escriptors, juristes, notaris, homes de la cancelleria, ambaixadors, tot plegat, una nova fornada d'homes preparats intel lectualment $\mathrm{i}$ amants del saber, són conscients de la seva vàlua i del paper importantíssim que desenvolupen en una societat, la del segle XV, que podríem anomenar 'moderna' respecte a la centúria anterior. Sabedors, a més, del poder que comencen a tenir com a estament social, no

33 L'episodi ha estat analitzat, de manera molt precisa i esclaridora, per Butinyà (2001: 43-47).

34 De l'antiguitat clàssica, cal només recordar Juvenal (2007: 402): «Nobilitas sola est atque única virtus». Tot i que el tópos va tenir ressò al llarg de l'Edat Mitjana -Sèneca i, després, Boeci, havien estat referents importantíssims-, són els humanistes italians, especialment els del segle XV, qui fan del concepte poc menys que una doctrina. Vegeu Miguel (2009: 54-57) per a una explicació més detallada de la relació virtut-noblesa present a la nostra novel la; també se n’ocupa d'aquest binomi Butinyà (2001: 308) i, més abastament, aplicant-lo a la noblesa, a les acaballes de l'Edat Mitjana, però prenent com a referencia el Curial, en un treball posterior (2009: 292-311). Vegeu, a més, les significatives valoracions de Soler (2016: 2220-2235). 
Jeroni Miguel Briongos. Curial e Güelfa, un nou món per a un nou cavaller: espais literaris en un entorn humanístic

dubten a proclamar la importància de la virtus com un mitjà per aconseguir el reconeixement social dels seus mèrits i, en conseqüència, a assolir la noblesa. Aquest és, ni més ni menys, l'ambient que envolta el nostre Anònim, i Curial n'és l'exemple d'aquests afanys: al final del seu llarg trajecte, i gràcies a la seva nobilitas, esdevé un home íntegre, es casa amb la Güelfa i assoleix el títol de príncep d'Orange.

\section{Valoracions finals}

Com deia en començar aquest estudi, podem considerar el Curial e Güelfa una obra moderna i, per aquesta raó, he intentat allunyar de la meva anàlisi certes interpretacions que han vist la novel la com un producte de «la tardor medieval». Els estudis filològics dels darrers anys, en canvi, estan apropant les seves valoracions cap als postulats de l'humanisme italià que van difondre Petrarca i Boccaccio, sobretot, i, posteriorment, els autors del Quattrocento, inserint la tasca literària de l'anònim autor en l'ambient cultural i social que es vivia a la península itàlica i, més concretament, a la cort d'Alfons el Magnànim. ${ }^{35}$ Més enllà de les reminiscències de l'àmbit cavalleresc medieval que trobem a l'obra, he intentat posar en relleu alguns detalls d'aquest món humanístic, els paisatges del qual determinaran la formació d'un 'nou' cavaller, Curial -que serà expressió, també, d'aquest 'nou' univers-, i mostrar part dels valors intrínsecs literaris que l'obra posseeix. N' hem vist alguns detalls: la llengua emprada, per exemple, que es caracteritza pel seu equilibri entre el registre culte i el col loquial, per la claredat i per una expressió acurada; la prosa, que es fonamenta en una exquisida tècnica de la imitatio a l'hora d'utilitzar les fonts literàries; un text que, al meu entendre, està pensat per al gaudi del grup de coneguts i amics que formaven part del cercle cortesà de l'Anònim, molts d'ells lletraferits i «Scientífichs» com el nostre escriptor. Un altre detall, tal volta el més significatiu: la voluntat clara, expressada per l'autor de forma reiterada, de valorar la importància de l'estudi: sense aquest, les capacitats de l'home queden minvades, i Curial n'és l'exemple. Arribar a ser un cavaller íntegre i assolir la fita que persegueix, casar-se amb la Güelfa, li suposa passar per la dura escola de la vida; així, haurà de superar un munt d'obstacles que el posaran a prova, sigui en l'aspecte cavalleresc, sigui en el sentimental i anímic, per recuperar el seu jo autèntic i trobar l'bomo interior. ${ }^{36}$ Després, quan

35 Novament, Butinyà $(2001,272)$ introdueix un matís molt escaient en sostenir que «la actitud de considerar el Curial como una obra medieval oscura con un alto índice de signos misteriosos, que se yergue con un criterio estrictamente positivista (...), pierde consistencia ante la posibilidad de unos ojos humanistas que entendieron ese lenguaje lleno de riqueza literaria y lleno de guiños de signo historicista». I Soler (2016: 1568) explica que «L'escriptor de Curial e Güelfa ja no participa d'aquesta visió medieval, escolàstica i cristianitzadora dels clàssics de l'Antiguitat. Ell ja treballa amb una mentalitat d'autor profà, molt pròxima a la dels humanistes contemporanis, dels quals ha après idees, actituds i aspiracions».

36 Lucreci (1992: 170), al seu De rerum natura (III, 55-58), ens deixà la bella imatge de com és d'útil prendre l'home en consideració un cop que ha après de les escomeses de les adversitats, atès que, només així, del fons de la seva ànima, sortiran las paraules, trencarà la màscara que duu i descobrirem la seva essència: «Quo magis in dubiis hominem spectare periclis//convenit adversisque in rebus noscere qui sit;//nam verae voces tum demum pectore ab imo// eliciuntur et eripitur persona, manet res». 
Jeroni Miguel Briongos. Curial e Güelfa, un nou món per a un nou cavaller: espais literaris en un entorn humanístic

torni novament als llibres, es farà mereixedor de l'autèntica nobilitas, la que s'obté a través de la virtus, no l'heretada. Vet aquí un model de cavaller guerrer, noble, cortesà, polític i culte, que harmonitza a la perfecció -un reflex del que serà el paradigma de cavaller renaixentista, dibuixat magistralment al Cortigiano - dignitat cavalleresca i saber, en consonància amb el nou model de societat que s'està construint a la Itàlia d'aquest període i amb els valors més pregons de l'humanisme. 
Jeroni Miguel Briongos. Curial e Güelfa, un nou món per a un nou cavaller: espais literaris en un entorn humanístic

\section{Bibliografia}

Agustí, Sant (1948) De la verdadera religión, Obras de San Agustín, IV, Capanaga, V. et al. (eds.),

Madrid, Biblioteca de Autores Cristianos.

_. (2009) El maestro. Obras completas, III, Capanaga, V. (ed.), Madrid, Biblioteca de Autores Cristianos.

Alberti, L. B. (1980) I libri della famiglia, Romano, R. / Tenenti, A. (eds), Torino, Einaudi.

Aramon i Serra, R. (1930) (ed.) Curial e Güelfa, Barcelona, Barcino, 3 vol.

Badia, L. (1987) «La segona visió mitològica de Curial: Notes per a una interpretació de l'anònim català del segle XV Curial e Güelfar,, dins Camprubí, M. et al. (eds.) Estudis de Llengua i Literatura Catalanes XIV. Miscel Vlania Antoni M. Badia i Margarit / 6, Publicacions de l'Abadia de Montserrat.

Badia, L. \& Torró J. (2011) (eds.) Curial e Güelfa, Barcelona, Quaderns Crema.

Badia i Margarit, A. M. (1994 i 1995) «La impronta renacentista en las letras catalanas: latín y romance en los siglos XV y XVI», Revista de Lenguas y Literaturas Catalana, Gallegay Vasca, IV, pp. 165-180.

- (1999) Les «Regles de esquivar vocables» $i$ «La qüestió de la llengua», Barcelona, Institut d'Estudis Catalans.

Boeci, S. (2010) La consolarione della filosofia, Moreschini, C. (ed.), Torino, UTET Libreria.

Butinyà Jiménez, J. (2001) Tras los orígenes del Humanismo: el «Curial e Güelfa», Madrid, UNED.

- - (2004) «Algunas consideraciones sobre la poética medieval en el humanismo catalán: Bernat Metge y el Curial e Güelfai, Revista de poética medieval 12, pp. 11-52.

—_. (2009) «Les noves aristocracia i noblesa a les acaballes de l'Edat Mitjana a través de la novel la catalana Curial e Güelfar, Mirabilia, 9, pp. 292-311.

- . (2012) «Construir l'humanisme reconstruint la cultura i les fonts del Curial», dins Ferrando, A. (ed.) Estudis lingüistics $i$ culturals sobre «Curial e Güelfa», I, Amsterdam/Philadelphia, John Benjamins Publishing Company, pp. 201-234.

—. (2015/2) «La introducción del Humanismo en la Península Ibérica», Mirabilia, 21, pp. 197221.

Cappelli, G. M. (2000) «Hércules en la encrucijada entre Italia y España», dins Freixas, M. / Iriso, S. (eds.) Actas del VIII Congreso de la AHLM (Santander, 22-26 de septiembre de 1999), Santander, Gobierno de Cantabria, vol. I, pp. 503-513.

- (2007) El Humanismo italiano. Un capitulo de la cultura europea entre Petrarca y Valla, Madrid, Alianza Editorial.

Cingolani, S. M. (1994) «Finzione della realtà e realtà della finzione. Considerazioni sui modelli culturali del Curial e Güelfar, dins Badia L. / Soler, A. (eds.) Intel Vlectuals i escriptors a la Baixa Edat 
Jeroni Miguel Briongos. Curial e Güelfa, un nou món per a un nou cavaller: espais literaris en un entorn humanístic

Mitjana, Barcelona, Curial Edicions Catalanes, Publicacions de l'Abadia de Montserrat, pp. 129159.

Díaz de Games, G. (2014) El Victorial, Beltrán, R. (ed.), Madrid, Real Academia Española.

Escartí, V. J. (2012) «La imatge de l'escriptura al Curial e Güelfa. Usos i funcions», dins Ferrando, A. (ed.) Estudis lingüistics i culturals sobre «Curial e Güelfa», I, Amsterdam/Philadelphia, John Benjamins Publishing Company, pp. 253-276.

Espadaler, A. (1984) Una reina per a Curial, Barcelona, Quaderns Crema.

Ferrando Francés, A. (2007) (ed.) Curial e Güelfa, Toulouse, Anacharsis Éditions.

(2012) «Precaucions metodològiques per a l'estudi lingüístic del Curial e Güelfa», dins Ferrando, A. (ed.) Estudis lingüistics $i$ culturals sobre «Curial e Güelfa», I, Amsterdam/Philadelphia, John Benjamins Publishing Company, pp. 31-87.

—_. (2018) «El model lingüístic de Curial e Güelfa», Revista Valenciana de Filologia, 2, pp. 39-84.

Galves, J. (2007) (ed.) Curial e Güelfa, Barcelona, Edicions 62.

Garin, E. (1978) L'umanesimo italiano, Bari, Editori Laterza.

Gonzàlvez i Escolano, H. (2000) «El debat medieval de les armes i les lletres: l'aportació catalana del Curial e Güelfa», dins Freixas, M. / Iriso, S (eds.) Actes del VIII Congreso Internacional de la Asociación Hispánica de Literatura Medieval (Santander, 22-26 de septiembre de 1999), Santander, Gobierno de Cantabria, vol. 1, pp. 869-881.

_- (2004) «Els models caballerescos en el Curial e Güelfa», dins Friedlein R. / Neumeister S. (eds.) Vestigia Fabularum. La Mitologia Antiga a les Literatures Catalana i Castellana entre l'Edat Mitjana i la Moderna, Barcelona, Curial Edicions Catalanes, Publicacions de l'Abadia de Montserrat, pp. 31-48.

Juvenal, D. G. (2007) Sátiras, Cortés Tovar, R. (ed.), Madrid, Cátedra.

López de Mendoza, I. (2003) Poesías Completas, Kerkhof, M.P.A.M. / Gómez Moreno, A. (eds.), Madrid, Castalia.

Lucreci, T. (1992) La natura delle cose, Milanese, G. (ed.), Milano, Oscar Mondadori.

Mclaughlin, M. L. (1998) «El humanismo y la literatura italiana», dins Kraye, J. (ed.) Introducción al bumanismo renacentista, Cambridge, Cambridge University Press.

Miguel, J. (2004) La corte napolitana del Magnánimo. Jordi de Sant Jordi, dins www.liceus.com (Biblioteca Virtual de Humanidades: Literaturas Hispánicas no Castellanas).

- (2009) «Virtus et sapientia, elements integradors de la nobilitas de Curial», eHumanista, 13, pp. $38-60$.

Miralles, C. (2012) «Dues notes sobre el Curial e Güelfa», dins Ferrando, A. (ed.) Estudis lingüistics i culturals sobre «Curial e Güelfa», I, Amsterdam/Philadelphia, John Benjamins Publishing Company, pp. 429-461.

SCRIPTA, Revista internacional de literatura i cultura medieval i moderna, núm. 12/ desembre 2018/pp. 168-188 ISSN: 2340 - 4841 doi:10.7203/SCRIPTA.11.13671 
Jeroni Miguel Briongos. Curial e Güelfa, un nou món per a un nou cavaller: espais literaris en un entorn humanístic

Montemagno, B. da (1976) De nobilitate, dins Garin, E. (ed.) Prosatori latini del Quattrocento, II, Torino, Einaudi, pp. 142-65.

Petrarca, F. (1977) Le familiari, Bianchi, E. (ed.), Torino, Einaudi.

—. (1992) De vita solitaria, Noce, M. (ed.), Milano, Arnaldo Mondadori Editore.

- (2007) Carta a la posteritat. Carta a Boccaccio, Bastardas, J. / Quetglas, P. J. (eds), Barcelona, Adesiara.

Piccolomini, E. S. (2002) De liberorum educatione, dins Kallendorf, C. W. (ed.) Humanist Educational Treatises, Cambridge/Massachusetts/London, The Tatti Renaissance Library, pp. 126-259.

Rico, F. (1974) Vida u obra de Petrarca I. Lectura del «Secretum», Padova, Antenore Editrice.

-. (2002) El sueño del humanismo, Barcelona, Destino.

Russell, P. E. (1985) Traducciones y traductores en la península ibérica (1400-1550), Bellaterra, Universitat Autònoma de Barcelona.

Sèneca, L. A. (2009) Lettere a Lucilio, II, Monti, G (trad.), Milano, Rizzoli.

Soler, A. (2016) La cort napolitana d'Alfons el Magnànim: El context de «Curial e Güelfa», tesi doctoral, Universitat de València, Facultat de Filologia, Traducció i Comunicació, Departament de Filologia Catalana.

Torró Torrent, J. (2002) (ed.) Curial e Güelfa, Barcelona, Hermes.

Villena, E. de (1994) Obras completas, I, Cátedra, P. M. (ed.), Madrid, Turner. 